\title{
Martin Will
}

\section{Selbstverwaltung der Wirtschaft}

Recht und Geschichte der Selbstverwaltung in den Industrie- und Handelskammern, Handwerksinnungen, Kreishandwerkerschaften, Handwerkskammern und Landwirtschaftskammern

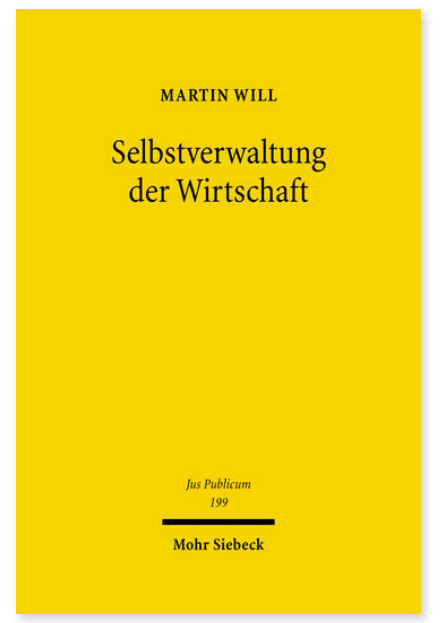

2010. XLII, 977 Seiten. JusPubl 199

ISBN 978-3-16-151280-3

DOI 10.1628/978-3-16-151280-3

eBook PDF 204,00€

ISBN 978-3-16-150705-2

Leinen $204,00 €$
Die Selbstverwaltung der Wirtschaft ist mit ihrer im Mittelalter wurzelnden Geschichte die traditionsreichste Form der Selbstverwaltung. Heute verwalten Millionen von Berufsträgern und Unternehmen in 80 Industrie- und Handelskammern, 53 Handwerkskammern, 320 Kreishandwerkerschaften, 5500 Handwerksinnungen und 7 Landwirtschaftskammern einen umfangreichen wirtschaftlichen Aufgabenkreis. Die Partizipation erschöpft sich dabei nicht in der Wahl der Repräsentativversammlungen. Vielmehr engagieren sich zehntausende von Berufsträgern aktiv ehrenamtlich in den Organen der Selbstverwaltungskörperschaften. Erstmals wird das Recht der Selbstverwaltung der Wirtschaft in seiner historischen Entwicklung und seinem aktuellen Stand konsequent aus dem Blickwinkel der Partizipation analysiert. Damit geraten zugleich die demokratischen Potentiale der Selbstverwaltung der Wirtschaft ins Blickfeld.

Martin Will Studium der Rechtswissenschaften, der Geschichts- und Kulturwissenschaften, der Philosophie sowie der Sinologie; 1997 LL.M. (Cambridge); 1999 Promotion zum Dr. iur.; 2007 Habilitation; 2008 Promotion zum Dr. phil.; 2010 Professur für Öffentliches Recht an der Universität zu Köln; 2011 Lehrstuhl für Staatsrecht, Verwaltungsrecht, Europarecht، Recht der Neuen Technologien sowie Rechtsgeschichte an der EBS Universität für Wirtschaft und Recht, Wiesbaden; 2014 Beauftragter der Unabhängigen Wissenschaftlichen Kommission beim Bundesministerium der Justiz für die Aufarbeitung der NS-Vergangenheit; 2016 Mitglied des Hessischen Verfassungskonvents.

\section{Jetzt bestellen:}

https://mohrsiebeck.com/buch/selbstverwaltung-der-wirtschaft-9783161512803?no_cache=1

order@mohrsiebeck.com

Telefon: +49 (0)7071-923-17

Telefax: $+49(0) 7071-51104$ 